large population of military and towns-people. A chapter follows on the Saxon period in which the author revels-rightly so, as they were true sons of the soil : the vast majority of the villages in the central and southern parts of England have Saxon names and were presumably founded by them, being cut out from the primeval forest, though how exactly this was done is not known. By the time of the Domesday survey, however, English agriculture was already highly developed.

From Norman times onward the picture is much more complete: Mr. Trow-Smith has cast his net widely and has an eye for picturesque detail. $\mathrm{He}$ points out that in the Middle Ages more of the grain produced in England was drunk than was eaten. He recalls the story of the thirty canons of St. Paul's who, in 1286, were said to have drunk two-thirds of the brew from 175 quarters of barley, 175 quarters of wheat and 720 quarters of oats-apparently averaging 1,500 gallons of ale apiece in the year-33 pints a day. One can only add, adapting one of Mr. Churchill's crisp phrases : "Some canon, some thirst".

Written accounts of English agriculture begin in the early part of the thirteenth century with Walter of Henley's "Husbandry", two anonymous treatises, and Bishop Grosseteste's "Rules" of about 1240 . They were published in 1890 with a translation by Elizabeth Lamond and a description by Mr. Cunning. ham, and are liberally drawn upon by the author. Then followed the time of plagues and pestilences culminating in the Black Death of 1348 , which greatly reduced the numbers of farm workers: recovery, however, seems in many places to have been rapid, suggesting that there had previously been a good deal of redundant labour in the villages, as often happens in peasant communities. The changes resulting from the subsequent decay of the manorial system and the long series of enclosures are well described, and the author then deals with the great developments of the seventeenth century.

During the Civil Wars some Royalist landowners went as refugees to Flanders, where they saw agricultural practices much in advance of anything they had known in Britain-in particular the culture of clover, sown grasses and other fodder crops that enabled livestock husbandry to be fully integrated with arable husbandry : this forms the basis of some of our best modern systems. The author gives numerous quotations from contemporary writers and a good selection of illustrations showing the implements they used. He emphasizes the fact that ley farming, new to some of this generation, was introduced in Britain in the seventeenth century.

The author rather condemns the high farming of the mid-nineteenth century because it relied for its success on oil cakes and meals got from overseas countries "at the expense of the fertility of foreign soils, and many parts of an eroded world are to-day paying the piper for the tune played at the call of the English mid-Victorian yeoman". This is scarcely fair. The overseas farmer had not taken up land at the behest of the mid-Victorian yeoman but in order to live: not wishing for a low-level subsistence farming, he produced for the market. He was free to dispose of his produce however he liked. Great Britain offered the best terms and he sent it here. The erosion set in not because he sold the grainwhich he had to do in any event-but because he was using in semi-arid conditions cultivation methods developed for humid regions, and it was long before appropriate methods were worked out. The English farmer acted rightly in buying extra feeding stuffs while he had the chance - the Danish and Dutch farmers later on did the same to their great advantage; he is equally right in producing more of his feedingstuffs at home now that he cannot buy from abroad.

A few errors have slipped into the text. The Rothamsted dates are wrong. The Broadbalk experiments were started in 1843 , three years after the publication of Liebig's book, not ten years as the author states; Lawes's experiments on superphosphate had been started about 1838. Liebig did not demonstrate the effect of chemical nutrients on crop growth; he used the results obtained by others. One would like to have seen John Andrews, the farm labourer of Debenham, given the credit for discovering Chevallier barley: it was he that found it and grew it first; but the local parson, the Rev. John Chevallier, multiplied it for distribution so it was called after him. Apart from these minor defects the book is very interesting and well worth reading.

E. John Russeli

\section{CONTRIBUTIONS TO MATHEMATICAL STATISTICS}

\section{Contributions to Mathematical Statistics}

By Prof. R. A. Fisher. (Wiley Publications in Statistics.) Pp. xvii + 658. (New York : John Wiley and Sons, Inc.; London : Chapman and Hall, Ltd., 1950.) 60s. net.

THIS book consists of reproductions of a selection of forty-two of the author's more important scientific papers, together with a biography by Prof. P. C. Mahalanobis originally published in Sankhya. However, it differs in many ways from the ordinary volumes of 'collected works'. The papers have been selected by the author, and each paper has been prefaced by a short note indicating the circumstances which gave rise to it, and its relation to the common knowledge, or common misapprehensions, current at the time it was written. The papers are reproduced photographically, to the original size, with manuscript corrections and amendments. This produces a pleasing variety of text, and ensures that no new printing errors are introduced. The corrections that have been made are also apparent, a point which is of importance if the results have been used as a basis for subsequent work. Further, this method of reproduction has the very great advantage that it has enabled the book to be produced at a much lower cost, and with far less proof reading, than would otherwise have been possible. In this connexion, indeed, the generosity of the editors of the various scientific journals in permitting reproduction of their papers-only one journal, Metron, refused permission to republish - is to be warmly commended.

The selection of papers has been well done, though it is inevitable that there will be some disagreement as to what constitutes the perfect choice. One might, for example, have wished to see included the paper on "The Influence of Rainfall on the Yield of Wheat at Rothamsted" (Phil. Trans. Roy. Soc., B, 213, 89 ; 1924), which contains a very elegant and original method of estimating the effect of rainfall at different times of the year, if necessary in preference to the earlier and less important paper on the variation in wheat yield from the same field ("Studies in Crop Variation. I. An Examination of the Yield of Dressed Grain from Broadbalk", J. Agric. Sci., 11, 
$107 ; 1920)$. As an example of historical research, the paper on Mendel's work ("Has Mendel's Work been Rediscovered?", Ann. Science, 1 (2), 115 ; 1936), which is almost inaccessible in the original, is of lasting interest, while the relatively trivial paper on the half-drill strip method by Barbacki and Fisher ("A Test of the Supposed Precision of Systematic Arrangements", Ann. Eugen., 7, 189; 1936) seems scarcely worth reproduction without at least a refer. ence to 'Student's' subsequent and not wholly unjustified criticism of it.

The collection will be of immense value to all mathematical statisticians, particularly those of the younger generation who have not had direct contact with the original articles when they appeared. As Fisher himself stresses in the preface, reference to original sources of mathematical research tends to be neglected-indeed, it is only by publications such as the present one that the ordinary student can hope to make any comprehensive study of the works of a single author. In the present instance, the study is of interest and importance, not only in revealing how the subject has developed, but also because many of the results obtained and methods described are still only available in the original papers.

The book is also a worthy monument to Fisher's achievement in mathematical statistics. Even to those who are closely acquainted with his work, it brings fresh realization of its immense scope and the genius that marks so much of it.

From the point of view of a student, there are, of course, defects in the use of collected papers by a single author in the study of a subject, in that only one side of a controversial issue is presented. In such a case what is really required is a collection of papers by different authors dealing with the same subject. The same is true when a subject is developed concurrently by several authors. Perhaps if the method of reproducing scientific papers adopted in the volume is found to be generally acceptable, collections of this kind dealing with specific subjects might be attempted.

F. YATES

\section{POLLEN ANALYSIS}

Text-Book of Modern Pollen Analysis

By Knut Fægri and Johs. Iversen. Pp. 168. (Copenhagen : Ejnar Munksgaard, 1950.) 16 Danish er.

$7 \mathrm{O}$ quote from the preface of this little work :

"Pollen analysis is still a very young science ... . and [it] has developed swiftly during the last 10 years". The aim of the authors, two well-known Scandinavian workers, has been to set forth, fairly exhaustively but simply, the technique in all its aspects and applications. This has been done in seventeen (unnumbered) chapters, which cover the subject thoroughly, from a short historical introduction to the latest suggested aid in pollen-grain identification-a perforated card key. The over-all result is an excellent book that cannot fail to be of very great help to everyone, mature worker or beginner, concerned with the science.

Some points, of course, in my opinion at any rate, invite criticism. In the chapter dealing with the pollen diagram, for example, it would have been more convenient for the reader if the example of a typical diagram (Pl. IX) had been inserted here instead of at the end of the book. As to the merits of different types of diagram, I have always held the opinion that the 'dissolved' (unhappy word) diagram as used by Dr. Godwin and his co-workers has much to recommend it for clarity and directness of appeal. It would have been helpful if an example of this type of diagram covering the (mainly peat) zones of the Post-Glacial Period had been inserted. The omission of any illustration of these zones is indeed strange, since pollen analysis, as we know it, after all was founded on peat; perhaps the answer to this riddle is to be found in the statement on p. 84 of the book, which reads: "For ordinary work one should never analyse peat if any sediment is available". This statement is altogether too sweeping. The 'ordinary' work of pollen analysis dealt, and still deals, with peat. Are we to understand, for example, that the fine work of Jessen on the Irish bogs, so recently published, is of little value? Surely not.

The pollen keys provided are 'artificial' keys, and result in many strange bed-fellows. They deal mainly with the pollen species likely to be found in deposits in north-west Europe. They will doubtless serve their purpose-but, as the authors are at pains to impress on their readers, a pollen herbarium is a sine qua non for the pollen analyst.

The book is pleasingly printed, and the authors acknowledge indebtedness to Miss Jean Allison and Mr. Philip Tallantire for linguistic advice and help in proof-reading. A number of awkward words and phrases have passed uncorrected, but these are not likely to mislead the serious reader. When a second edition is called for, however, as it well may be, the opportunity should be taken of correcting these solecisms-and making a good book better.

J. B. SIMPSON

\section{AMERICAN DECIDUOUS FORESTS}

\section{Deciduous Forests of Eastern North America}

By Prof. E. Lucy Braun. Pp. xiv+596. (Phila delphia and Toronto: The Blakiston Company, 1950.) 10 dollars.

7 HE deciduous forests of eastern North America are treated in this book predominantly from the descriptive point of view, and Prof. E. Lucy Braun adopts as a basis the view that those forests which to-day appear to have been little modified by man can be regarded as indicative of the climax com. munities of the original forest cover.

The deciduous communities dealt with are considered by the author to comprise nine major forest regions based upon physiognomy and similarity of floristic composition. Historic factors are recognized as playing an important part. Thus, the mixed mesophytic forest region of the unglaciated Appalachian plateau is not only particularly the home of the chestnut, Aesculus octandra, and the white basswood, Tilia heterophylla, but is also perhaps significantly the habitat of the tulip tree, of ancient lineage. This region is by far the richest in species, with a number of kinds of trees constituting the canopy, usually more than thirteen even in a small sample area, together with a rich herbaceous vegeta. tion some of the characteristic members of which have contributed to the beauty of gardens in England (for example, Trillium grandiflorum, Erythronium americanum, Phlox divaricata and Tiarella cordifolia). By contrast, the communities of the younger areas, where the forests are attributed to post-glacial immigration, exhibit only about half the number of arboreal species in the forest canopy, and the subordinate layers are floristically far less varied. 